\title{
Exploration on the Cultivation Mode of Innovative Postgraduates in Architecture and Civil Engineering Specialty Based on Global Perspective
}

\author{
Chen Weigong \\ School of Management \\ Qingdao University of Technology \\ Qingdao, China \\ ch.ylh@163.com
}

\author{
Wang Huihui \\ School of Management \\ Qingdao University of Technology \\ Qingdao, China \\ niepanxueya1111@126.com
}

\author{
Yue Lihong \\ School of Automotive and Transportation \\ Qingdao University of Technology \\ Qingdao, China \\ ch.yuelihong@163.com
}

\begin{abstract}
With the rapid development of social economy, the traditional construction and civil engineering graduate education is facing new development opportunities and serious challenges, cultivate a group of global vision and innovation ability of professionals has become an innovative country construction needs. In this paper, the existing educational mechanism is perfected from four aspects: teaching philosophy, teaching methods, teacher structure and academic exchange, and a set of distinctive high-level personnel training mode is established. The establishment of the model for the cultivation of a global vision of the construction and civil engineering professional innovative graduate students put forward a practical and feasible approach. The construction of the model will help the postgraduate education to form a multi-mode and multi-level new pattern, and then promote the internationalization of university talent education process, and ultimately enhance the international influence and competitiveness of China's innovative talents.
\end{abstract}

Keywords-architecture and civil engineering; global vision; innovative graduate students; training mode

\section{INTRODUCTION}

Graduate education is a comprehensive and systematic training model. It is the scientific embodiment of the goal of cultivating students, cultivating ideas, training principles and training methods and ways. At the same time, it is an important way to improve the academic level, scientific research ability and shaping personality [1]. Graduate education represents a country's level of educational development, which plays an important role in the development of national economy, politics and culture and the promotion of the national comprehensive strength. Thus, with the deepening of globalization of science and technology, cultivating with international competitiveness of top-notch innovative talent has gradually become the consensus of the development of graduate education. And as early as July 29, 2010 China published in the "national education reform and development

Graduate Education Innovation Program of Shandong Province in China (SDYY15043); Elite School Project of Qingdao University of Technology (MX6-001, MX4-094) of long-term planning programs (2010-2020)" has made it clear that "to carry out multi-level, wide-ranging educational exchanges and cooperation to improve China's education international level"[2]. However, graduate education as an important category of higher education, its existing training model is difficult to adapt to the needs of the times.

As a professional person in the field of construction and civil engineering, it is necessary to find out the problems in the practice of the project and make use of the generous professional knowledge and scientific methods to put forward new opinions on the technical problems in the project practice through rigorous engineering practice [3]. However, under the restriction of traditional talents training mode, there are many defects in the cultivation mode of postgraduates in our country. It is difficult to integrate with the well-known international universities and achieve universality in quality of graduate education. The construction industry is an important part of China's economic system, at the same time is the dominant factors to achieve the sustainable development of China's social and economic; it should be the process of internationalization of the country to cultivate more international competitiveness of professionals. To this end, the activation of the vitality of graduate training model for the construction and civil engineering graduate students to build a more scientific and efficient training platform to achieve the optimization and upgrading of graduate training model is imperative.

\section{CUltivation Standard OF InNOVATIVE POSTGRADUATES IN ARCHITECTURE AND CIVIL ENGINEERING}

As a professional degree, graduate students of architecture and civil engineering can only make it become the advanced applied talents to solve the practical problems of economic production and social development by clarifying its training objectives. Attention to the cultivation of graduate students' innovative ability not only directly affects the level of knowledge innovation in colleges and universities, but also the overall innovation ability of our country in the future. In view 
of this, in order to realize the self - cultivation of independent thinking ability, knowledge integration ability and innovation ability of graduate students, graduate students of innovative buildings and civil engineering should have profound theoretical knowledge, good academic communication ability and professional practical ability.

\section{A. Profound theoretical knowledge}

The education of graduate degree in architecture and civil engineering aims at cultivating high-level applied personnel in the field of civil engineering, which with a solid foundation of the theory and broad professional knowledge, has a strong ability to solve practical problems, can take professional or management work, and has a good professional quality [4]. Therefore, the innovative professionals not only have three-dimensional knowledge structure, but also are able to combine the knowledge and production practice. It is necessary to graduate students to be skilled use of solid basic knowledge to guide the production and master the modern technology approach, while the field of expertise in a direction with independent research, design, implementation, development, management and other capabilities.

\section{B. Mature academic communication skills}

With the continuous pace of modernization in China, the economic system is increasingly perfect, more and more important information sharing. Academic communication helps break the original thinking of professionals and injects elements of innovative thinking about openness, freedom, sociality, value, precision, agility, truthfulness and creativity. For the construction and civil engineering graduate students, it needs academic exchange activities to broaden their horizons, stimulate their creativity, rely on a good academic atmosphere to update and improve the existing knowledge system, and ultimately enhance their ability to solve practical problems.

\section{Professional practical ability}

The full-time Master of engineering can be straightforward for high level applied talents with good occupation accomplishment. As a result, the innovative ability of graduate students of architecture and civil engineering degree is also reflected in the practical ability of solving practical problems in engineering field based on professional knowledge. The practical ability of the professional graduate students can be explained in the case of information collection is complete, the use of existing knowledge system to analyze the problem and organize the existing human and material resources to solve the problem, and ultimately the ability to classify the problem. Professional practice ability is the embodiment of the comprehensive quality of full-time engineering master.

\section{Construction of Cultivation Model of InNovative Professional Degree Based on Global Perspective}

Graduate cultivation model refers to the standard style and mode of operation of the elements of the postgraduate cultivation process formed by the purpose of realizing the postgraduate cultivation (including the cultivation specifications) under the guidance of certain educational thoughts, educational theories and specific needs [5]. In this paper, this kind of culture mode is to cultivate innovative talents with international thinking. That is, in the current many imperfect or unreasonable restrictions, to maximize the liberation of the thinking of students, to stimulate students to complement their potential to achieve the established objectives in a suitable starting point. Based on the principle of adherence to the concept of personnel training, this paper has improved the international training mode of postgraduates to adapt to the development of the specialty from four aspects: teaching philosophy, teaching methods, teacher structure and academic exchange.

\section{A. Teaching philosophy}

For the architecture and civil engineering graduate students, should be generally recognized the training goal is to have pioneering and innovative spirit of the technical talents. Therefore, in training of graduate students, should pay more attention to the cultivation of critical thinking, and pay attention to the students to develop an independent, not superstitious authority of the thinking habits. To this end, the training model adheres to the open concept of teaching. Open teaching concept is based on students as the protagonist, with autonomy, cooperation and inquiry characteristics, pay attention to active learning ability and innovation ability. The open teaching idea can provide a favorable platform for the students to inspire and interact with each other, and provide students with independent practice process to ensure that the graduate students have a certain space in the free practice of innovation and practice.

\section{B. Teaching methods}

In order to make the existing graduate teaching and international teaching convergence, learn from the content of foreign teaching flexible, detailed and practical design of the teaching characteristics of teaching methods from the curriculum and teaching methods to explain.

In the curriculum, the first should refer to foreign related professional syllabus, purposeful introduction of foreign excellent original textbooks. In the course of the English textbook, the English language examinations will be carried out to develop the English thinking habits of graduate students and improve the ability of graduate students to read, write, understand and apply the professional knowledge in English. At the same time, to carry out English literature research courses, to encourage students to read a large number of English original literature and classic academic papers, in the literature to focus on practical examples and knowledge of the combination. Finally, reference the experimental courses of experimental laboratories in foreign laboratories and set them as a compulsory course to teach and study the experimental methods, techniques and content as a complete system.

In the implementation of teaching methods, should learn abroad will be classroom teaching and group discussion, the combination of systematic lectures and seminars or teaching and research combined teaching methods, using a variety of ways to deepen the graduate students on the course content of understanding and thinking. Moreover, to strengthen the basic curriculum teaching reform, scientific allocation of teaching resources, individualized. Through the implementation of English hierarchical curriculum teaching to effectively improve the English proficiency of graduate students and language application ability. That is, different levels of students with different degrees of difficulty of the course, the basis of the 
poor to strengthen the foundation, the comprehensive application ability is not up to enhance the comprehensive application ability. In the case of teachers and students can clearly target the case, the teaching content of the organization will be easier, the focus of the course to better grasp, the teaching and learning efficiency will be improved.

\section{Teacher structure}

The internationalization of higher education is first reflected in the internationalization of teachers, there is no international vision of the faculty to cultivate no international characteristics of the graduate students [6]. Thus, for the school, in order to strengthen the international graduate of the professional teaching, should increase teachers' overseas visits, the introduction of foreign quality education resources, and create an international teaching atmosphere. To explore the outstanding young teachers in the famous universities or key laboratories at home and abroad learning exchange program, and gradually introduce some advanced education ideas training courses, and the initial establishment of graduate training platform to promote the construction of graduate tutor team. Moreover, international experts and professors should be invited to give lectures or lectures on a regular basis so that students can directly experience the advanced teaching methods abroad, and can bring us fresh air in the field of scientific development in the field and provide a good reference for our teaching.

\section{Academic exchange}

The development of professional graduate students with a global perspective requires an international platform to expand their international research horizons. First of all, to encourage outstanding graduate students to participate in the famous academic conference at home and abroad, so that students have the opportunity to understand the cutting-edge research topics, open up horizons, while access to the latest scientific research information, put forward innovative ideas of academic point of view. Second, encourage graduate students to participate in international competitions, under the impact of different cultures and values to enhance the international competitiveness of graduate students. In addition, we will carry out domestic and international cooperation and exchange projects to attract foreign students to study and promote the exchange of Chinese students and foreign students, increase understanding. Finally, within the scope of the conditions allowed to actively expanding the internationalization of graduate thesis research channels. Organize graduate students to conduct overseas exchange programs, to encourage students to follow the relevant academic papers at the forefront of international academic, and employ foreign professors to carry out research work and academic writing to carry out joint guidance.

The construction of the international academic exchange platform will help students from different angles to look at the problem, think about the problem, what is more, put forward new ideas, new ideas, new solutions to solve the problem. It also helps to narrow the gap with other developed countries, and promote the internationalization of education in China.

\section{The Role of Cultivation Model in Promoting the INTERNATIONALIZATION OF INNOVATIVE POSTGRADUATES IN ARCHITECTURE AND CIVIL ENGINEERING}

In terms of theoretical knowledge, the model changes the past knowledge reserve concept and adjusts the teaching model. On the one hand, the training mode of the relevant disciplines of the original foreign language teaching materials and emerging disciplines into the teaching system; on the other hand, it will shift from the past to professional theory and knowledge accumulation as the center to focus on both the accumulation and emphasis on professional research and innovation ability training. It is through the opening of engineering practice courses and foreign classical literature research courses, etc., to cultivate in the professional knowledge and practical ability to accumulate on the fully prepared, with international competitiveness of practical talents.

In terms of academic exchange, through the cooperation of Chinese and foreign cooperation, funding to participate in international conferences and international academic forums and other international academic exchange platform for students to create a strong academic atmosphere, in order to broaden the vision of graduate students and the awareness of the hot issues of the discipline. That encourages graduate students to understand their own professional areas of the latest research progress, actively participate in scientific research activities for the future to achieve scientific research results to lay the foundation for international exchanges.

In the aspect of practice ability, it breaks the gap between practice and research, makes up the gap between theory and reality, and enhances the innovation and autonomy of graduate students in facing realistic challenges. So that students have a sound knowledge structure, good humanistic literacy, a solid scientific foundation, keen practical innovation and international exchange and cooperation ability, can be applied to the theory and methods to solve the future of major scientific issues and engineering challenges.

\section{SUMMARY}

(1)Graduate education should closely follow the development of world science and technology, thus, in order to achieve graduate education and international community professionals in the benign interaction, this paper puts forward the cultivation mode of innovative talents for postgraduates of architecture and civil engineering based on global perspective.

(2)This paper puts forward the cultivation mode of internationalization of postgraduates, including teaching philosophy, teaching methods, teacher structure and academic exchange, in the case of cultivating innovative graduate students in architecture and civil engineering. Through the expansion and training of the professional graduate students in the global vision, it enriches the training mechanism of postgraduates in our country, and provides a way to realize the education of our country and international standards. 


\section{ACKNOWLEDGEMENTS}

This research was financially supported by the Graduate Education Innovation Program of Shandong Province in China (SDYY15043), Elite School Project of Qingdao University of Technology (MX6-001, MX4-094).

\section{REFERENCES}

[1] Ning-ke Wang. Analysis on the Transformation of Postgraduate Cultivation Mode from the Perspective of Collaborative Innovation,J . The Science Education Article Cultures, 2015(12): 26-27.(In Chinese)

[2] National education reform and development of long-term planning programs(2010-2020)[EB/OL].(2010-07-29) http://www.gov.cn/jrzg/2010-07/29/content_1667143.htm(In Chinese)

[3] Jin-hua Ding. A Study on the Ways of Cultivating Innovative Talents of Architectural Graduate Students in "Five in One" ,J. Sichuan Architecture, 2015, 35(1): 54-56.(In Chinese)

[4] Gong-xun Wang, Ming-qiao Zhu and Chao-feng Zeng, et al, Study on the Reform and Innovation of Curriculum System for Full-time Postgraduates Majoring in Architecture and Civil Engineering, J. Education Forum. 2016(3): 80-81.(In Chinese)

[5] Xiao-lin Wu, Zheng-fu Ning, Chang-zheng Qi .Demand-Driven Innovation Model to Cultivate Excellent Oil Engineers, J.Academic Degrees \& Graduate Education. 2013(9):4-8. (In Chinese)

[6] Jia-cheng Zhang, Xiao-hui Liu,Tao-ran Li.Reflections on the New International Business Personnel Training Based on Internationalized Perspective, J. The Science Education Article Collects. 2012(17): 43-44.(In Chinese) 